\title{
EXTENDED KALMAN FILTER FOR ESTIMATION OF CONTACT FORCES AT WHEEL-RAIL INTERFACE
}

Khakoo Mal

PhD Scholar, Department of Electronic Engineering, Mehran University of Engineering and Technology, Jamshoro, (Pakistan). E-mail: 17phdiict05@students.muet.edu.pk ORCID: https://orcid.org/0000-0002-5754-0441

Imtiaz Hussain

Associate Professor, Electrical Engineering. DHA Suffa University. Karachi, (Pakistan). E-mail: imtiaz.hussain@dsu.edu.pk ORCID: https://orcid.org/0000-0002-7947-9178

\section{Bhawani Shankar Chowdhry}

Professor Emeritus.

Mehran University of Engineering and Technology. Jamshroo, (Pakistan). E-mail: bhawani.chowdhry@faculty.muet.edu.pk ORCID: https://orcid.org/0000-0002-4340-9602

Tayab Din Memon

Associate Professor, Department of Electronics. Mehran University of Engineering and Technology. Jamshoro, (Pakistan). E-mail: tayabdin82@gmail.com ORCID: https://orcid.org/0000-0001-8122-5647

\section{Gitación sugerida Suggested citation}

Mal , K., Hussain, I., Chowdhry, B. S., y Memon, T. D. (2020). Extended Kalman filter for estimation of contact forces at wheel-rail interface. 3C Tecnología. Glosas de innovación aplicadas a la pyme. Edición Especial, Abril 2020, 279-301. http://doi.org/10.17993/3ctecno.2020.specialissue5.279-301 


\section{ABSTRACT}

The wheel-track interface is the most significant part in the railway dynamics because the forces produced at wheel-track interface governs the dynamic behavior of entire vehicle. This contact force is complex and highly non-linear function of creep and affected with other railway vehicle parameters. The real knowledge of creep force is necessary for reliable and safe railway vehicle operation. This paper proposed model-based estimation technique to estimate non-linear wheelset dynamics. In this paper, non-linear railway wheelset is modeled and estimated using Extended Kalman Filter (EKF). Both wheelset model and EKF are developed and simulated in Simulink/MATLAB.

\section{KEYWORDS}

Railway dynamics, Wheel-rail interface, Model-based estimation, Extended Kalman Filter. 


\section{INTRODUCTION}

The main element of any study of rolling stock behavior is the wheel-track interaction patch (Simon, 2006). All the forces which help and direct the railway vehicle transmit via this narrow area of contact and knowing of the nature of these forces is most important for any investigation of the generic railway vehicle behavior (Melnik \& Koziak, 2017).

The Wheel-track condition information can be detected in real time to provide traction and braking control schemes for re-adhesion. For example, in Charles, Goodall and Dixon (2008) an indirect technique based on Kalman Filter (KF) is proposed for the estimation of low adhesion with wheel-track profile by using conicity and wheel-rail contact forces. A method using Kalman filter has also been introduced in Mei, Yu and Wilson (2008) and Hussain and Mei (2009) to identify the slip after evaluating the torsional frequencies in the axle of wheelset. Two indirect monitoring schemes using a bank of Kalman filters are proposed for (i) wheel slip detection and, (ii) real time contact condition and adhesion estimation in Hussain and Mei (2010, 2011). In Hussain, Mei and Ritchings (2013) and Ward, Goodall and Dixon (2011), the development of techniques based on Kalman-Bucy filter proposed for the estimation of wheel-track interface conditions in real time to predict the track and wheel wear, the development of rolling contact fatigue and any regions of adhesion variations or low adhesion.

However, due to nonlinear nature of wheel-rail dynamic behavior, Kalman-Bucy filter is difficult to use for entire operating conditions. A method using Heuristic non-linear contact model and Kalker's linear theory is proposed in Anyakwo, Pislaru and Ball (2012) for modeling and simulation of dynamic behavior of wheel-track interaction in order to discover the shape of interaction patch and for obtaining the tangential interaction forces generated in wheel-rail interaction area. On the basis of measurement of traction motor's parameters, (i) creep forces can be predicted by means of Kalman filter between roller and wheel (Zhao, Liang \& Iwnicki, 2012) and (ii) slip-slide is detected and estimated by using Extended Kalman Filter (EKF) (Zhao \& Liang, 2013).

A system based on two different processing methods, i.e., model-based approach using Kalman-Bucy filter and non-model based using direct data analysis, is presented for onboard indirect detection of low adhesion condition in Hubbard et al. (2013a, 2013b). 
However, the technique using yaw acceleration as a normalization method provides only a rough estimate and introduces a huge delay to obtain an estimate. A model-based technique using Unscented Kalman Filter (UKF) is proposed by Zhao et al. (2014) for estimation of creep, creep forces as well as friction coefficient from the behavior of traction motor. However estimators seem unreliable in some critical track conditions, hence still work is needed to monitor these wheel-rail parameters more effectively in real time.

A system based on the principles of synergetic control theory is proposed in Radionov and Mushenko (2015) to estimate adhesion moment in wheel-track contact point. Twodimensional inverse wagon model based on acceleration is developed in Sun, Cole and Spiryagin (2015) for evaluation and monitoring of wheel-rail contact dynamics forces. The results at higher speed are agreeable, however improvement in the model is further needed to reduce the error at all expected speeds. Another technique using multi-rate EKF state identification is presented in Wang et al. (2016) for detection of slip velocity by merging the multi-rate technique and Extended Kalman filter technique to identify the load torque of traction motor. On the basis of fitting non-linear model, EKF can also be applied to identify the wheel-track interaction forces and moments that takes into account the interface nonlinearities (Strano \& Terzo, 2018).

After reviewing the literature on condition monitoring of railway wheelset dynamics, it is observed that the problem to analyze wheelset conditions and update them to desired situation still needs to be improved in order to accomplish the expectation of railway vehicle to be really high speed, high comfort, more safer and economical means of transport across the world.

In this paper, Extended Kalman filter is designed for non-linear railway wheelset model to estimate lateral velocity and yaw rate of wheelset as well as creep and creep force. Polach formulae for creep force and friction coefficient are used in modeling of nonlinear wheelset. Both modeling of non-linear wheelset and designing of EKF are done in Simulink/MATLAB. 


\section{MODELING OF NON-LINEAR WHEELSET}

The motion of a railway vehicle is directed by interaction forces produced at wheeltrack contact, which change non linearly with respect to creepage and are affected by the unpredictable variations in the adhesion conditions (Hussain, 2012). A single solid-axle wheelset shown in Figure 1 is taken for modeling and estimation of wheel-rail conditions.

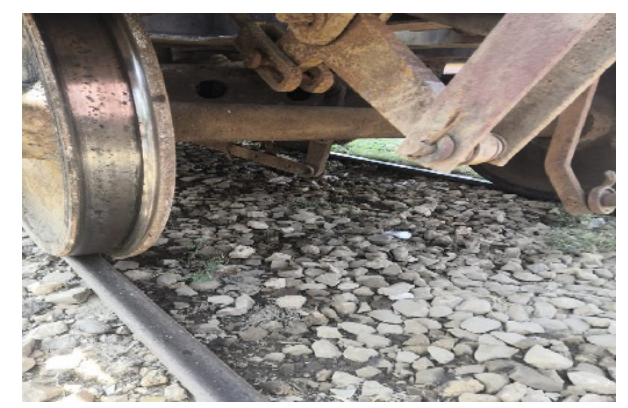

Figure 1. Railway wheelset [captured by author during field visit].

The creepages (the relative speed of the wheel to rail) of right and left wheels of wheels in longitudinal direction are expressed in following equations.

$$
\begin{aligned}
& \gamma_{x R}=\frac{\left(r_{0} \omega_{R}-v\right)}{v}-\frac{L_{g} \Psi^{\prime}}{v}-\frac{\omega_{R} \lambda_{w}\left(y-y_{t}\right)}{v} \\
& \gamma_{x L}=\frac{\left(r_{0} \omega_{L}-v\right)}{v}-\frac{L_{g} \Psi^{\prime}}{v}-\frac{\omega_{L} \lambda_{w}\left(y-y_{t}\right)}{v}
\end{aligned}
$$

The main objective of this paper is to develop a state of art technique to detect the changes in wheel-rail contact conditions. The term $\frac{\left(r_{0} \omega_{R}-v\right)}{v}$ in equations (1) and (2) does not involve lateral and yaw dynamics, hence can be excluded in simplified longitudinal creep equations because only yaw and lateral dynamics are sufficient for detecting these changes. Further , so the simplified creep equations used in above model become as:

$$
\begin{gathered}
\gamma_{x R}=-\frac{L_{g} \Psi^{\prime}}{v}-\frac{\lambda_{w}\left(y-y_{t}\right)}{r_{0}} \\
\gamma_{x L}=-\gamma_{x R}=\frac{L_{g} \Psi^{\prime}}{v}+\frac{\lambda_{w}\left(y-y_{t}\right)}{r_{0}}
\end{gathered}
$$


The creepages in lateral direction are expressed as:

$$
\gamma_{y R}=\gamma_{y L}=\gamma_{y}=\frac{y^{\prime}}{v}-\Psi
$$

While in equations (6) total creep of the wheels is depicted.

$$
\gamma_{i=\sqrt{\gamma_{j i}{ }^{2}+\gamma_{j i}{ }^{2}}}
$$

As the wheel-rail contact forces govern railway vehicle's dynamics are creep forces and are the function of creeps. The adhesion coefficient is the ratio of tangential force that is creep force to normal force and hence is also a function of creep. Figure 2 illustrates a classic nonlinear change of the adhesion coefficient with respect to creepage for all track conditions i.e. dry, wet, poor and worst conditions.

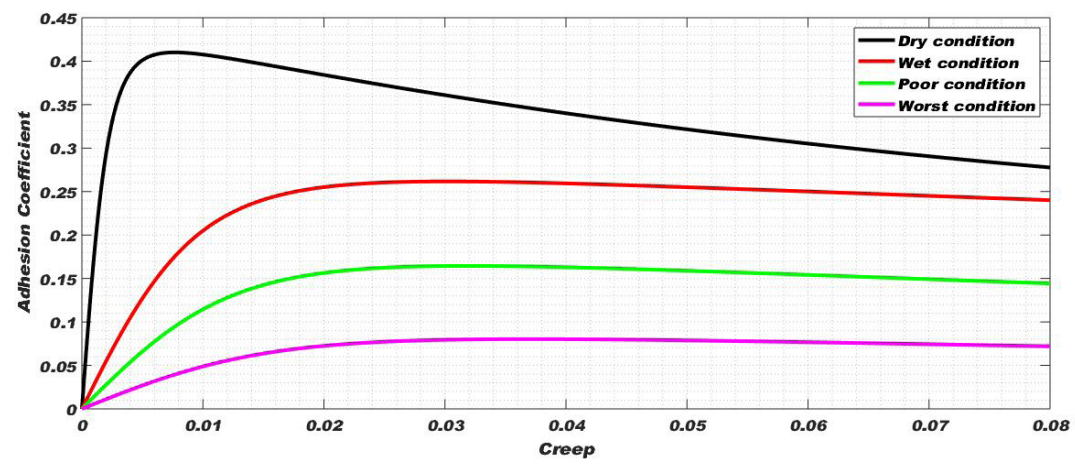

Figure 2. Creep v/s Adhesion Coefficient for all conditions of wheel-rail interface.

Following equations illustrate creep forces and adhesion coefficient.

$$
F_{j i}=\frac{F_{i} \gamma_{j i}}{\gamma_{i}}
$$

$i=$ Right and left wheels, $j=$ longitudinal and lateral directions

$F_{i}$ is the total creep force and can be calculated by Polach formula (Polach, 2005). 


$$
\left.F=\frac{2 \mathrm{NU}}{1+\left(\mathrm{k}_{A}\right)^{2}}+\arctan \left(\mathrm{k}_{S}\right)\right]
$$

Where $\mathrm{U}$ is friction coefficient, is gradient of the tangential stress in area of adhesion, $k_{A}$ is reduction factor in the area of adhesion and is the reduction factor in slip. Both $\mathrm{U}$ and are illustrated as:

$$
U=u_{0}\left[(1-A) e^{(-B \gamma v)}+A\right]
$$

Where $u_{0}$ is maximum friction coefficient at zero creep velocity, A is ratio of friction coefficient at infinity creep velocity to $u_{0}$ and $\mathrm{B}$ is coefficient of exponential friction decrease.

$$
=\frac{2}{3} \frac{a^{2} b \mathrm{c}}{\mathrm{NU}} \gamma
$$

While $\mathrm{a}$ and $\mathrm{b}$ are half-axes of contact ellipse and $c$ is coefficient of contact shear stiffness in $\mathrm{N} / \mathrm{m}^{3}$.

$$
\mu=\frac{F}{N}
$$

The equations of motion of railway wheelset at any point of creep curve of Figure 2 are expressed as (Hussain and Mei, 2009):

$$
\begin{gathered}
M_{v} \mathrm{x}^{\prime \prime}=F_{x R}+F_{x L} \\
m_{w} y^{\prime \prime}=-F_{y R}-F_{y L}+F_{C} \\
I_{w} \Psi^{\prime \prime}=F_{x R} L_{g}-F_{x L} L_{g}-K_{w} \Psi \\
\mathrm{T}_{s}=\mathrm{K}_{s} \theta_{s}+C_{S}\left(\omega_{R}-\omega_{L}\right) \\
\mathrm{I}_{L} \omega_{L}^{\prime}=\mathrm{T}_{s}-\mathrm{T}_{L} \\
\mathrm{I}_{R} \omega_{R}^{\prime}=\mathrm{T}_{m}-\mathrm{T}_{s}-\mathrm{T}_{R}
\end{gathered}
$$

Where $\theta_{s}=\int\left(\omega_{R}-\omega_{L}\right) \mathrm{dt}$ 
$F_{C}$ is centripetal force component and can be neglected when vehicle does not run in curves and $C_{S}$ is material damping of shaft which is normally very small. Hence both terms are not considered in this research.

In Table 1 detailed information of all parameters used in simulated wheelset model is given.

Table 1. Parameters used in modeling on non-linear wheelset.

\begin{tabular}{|c|c|c|c|c|}
\hline No. & Symbol & Parameter & Value & Unit \\
\hline 1 & $V_{x R}$ & Right wheel creep in longitudinal direction & calculated & ratio \\
\hline 2 & $\mathrm{y}_{\mathrm{xL}}$ & Left wheel creep in longitudinal direction & calculated & ratio \\
\hline 3 & $V_{y R}$ & Right wheel creep in lateral direction & calculated & ratio \\
\hline 4 & $\mathrm{Y}_{\mathrm{yL}}$ & Left wheel creep in lateral direction & calculated & ratio \\
\hline 5 & $V_{R}$ & Total creep of right wheel & calculated & ratio \\
\hline 6 & $V_{L}$ & Total creep of left wheel & calculated & ratio \\
\hline 7 & $r_{0}$ & Wheel radius & 0.5 (constant) & $\mathrm{m}$ \\
\hline 8 & $\mathrm{~L}_{\mathrm{g}}$ & Half gauge of track & 0.75 (constant) & $\mathrm{m}$ \\
\hline 9 & $\lambda_{w}$ & Wheel conicity & 0.15 (constant) & rad \\
\hline 10 & $\omega_{1}$ & Angular velocity of left wheel & calculated & $\mathrm{rad} / \mathrm{sec}$ \\
\hline 11 & $\omega_{R}$ & Angular velocity of right wheel & calculated & $\mathrm{rad} / \mathrm{sec}$ \\
\hline 12 & v & Vehicle's forward velocity & calculated & $\mathrm{m} / \mathrm{sec}$ \\
\hline 13 & y & Lateral displacement & Output & $\mathrm{m}$ \\
\hline 14 & $y_{t}$ & Track disturbance in lateral direction & input & $\mathrm{m}$ \\
\hline 15 & $\psi$ & Yaw angle & output & rad \\
\hline 16 & $F_{x R}$ & Right wheel creep force in longitudinal direction & calculated & Newton \\
\hline 17 & $\mathrm{~F}_{\mathrm{xL}}$ & Left wheel creep force in longitudinal direction & calculated & Newton \\
\hline 18 & $\mathrm{~F}_{\mathrm{yR}}$ & Right wheel creep force in lateral direction & calculated & Newton \\
\hline 19 & $\mathrm{~F}_{\mathrm{yL}}$ & Left wheel creep force in lateral direction & calculated & Newton \\
\hline 20 & $F_{R}$ & Total creep force of right wheel & calculated & Newton \\
\hline 21 & $F_{L}$ & Total creep force of left wheel & calculated & Newton \\
\hline 22 & $\mu$ & Adhesion coefficient between track and wheel & calculated & ratio \\
\hline 23 & $\mathrm{~N}$ & Normal load on wheel & constant & Newton \\
\hline 24 & $M_{v}$ & Vehicle mass & 15000 (constant) & $\mathrm{Kg}$ \\
\hline 25 & $I_{w}$ & Yaw moment of inertia of wheelset & 700 (constant) & $\mathrm{Kgm}^{2}$ \\
\hline 26 & $\mathrm{~K}_{\mathrm{w}}$ & Yaw stiffness & $5 \times 10^{6}$ (constant) & $\mathrm{N} / / \mathrm{rad}$ \\
\hline 27 & $m_{w}$ & Wheel weight with induction motor & 1250 (constant) & $\mathrm{Kg}$ \\
\hline 28 & $v_{0}$ & Vehicle's forward velocity at initial & input & $\mathrm{m} / \mathrm{sec}$ \\
\hline 29 & $\omega_{0}$ & Angular velocity of wheelset at initial & input & $\mathrm{Rad} / \mathrm{sec}$ \\
\hline 30 & $T_{m}$ & Torque of traction motor & input & $\mathrm{Nm}$ \\
\hline 31 & $\mathrm{~T}_{\mathrm{s}}$ & Torsional torque & calculated & $\mathrm{Nm}$ \\
\hline 32 & $T_{R}$ & Traction torque on right wheel & calculated & $\mathrm{Nm}$ \\
\hline
\end{tabular}




\begin{tabular}{|c|c|c|c|c|}
\hline No. & Symbol & Parameter & Value & Unit \\
\hline 33 & $\mathrm{~T}_{\mathrm{L}}$ & Traction torque on left wheel & calculated & $\mathrm{Nm}$ \\
\hline 34 & $\mathrm{I}_{\mathrm{R}}$ & Right wheel inertia & 134 (constant) & $\mathrm{Kgm}^{2}$ \\
\hline 35 & $\mathrm{I}_{\mathrm{L}}$ & Left wheel inertia & 64 (constant) & $\mathrm{Kgm}^{2}$ \\
\hline 36 & $\mathrm{~K}_{\mathrm{s}}$ & Torsional stiffness & 6063260 (constant) & $\mathrm{N} / \mathrm{m}$ \\
\hline 37 & $\theta_{\mathrm{s}}$ & Twist angle & calculated & $\mathrm{rad}$ \\
\hline
\end{tabular}

\section{DESIGNING OF EXTENDED KALMAN FILTER FOR ESTIMATING NON-LINEAR WHEELSET MODEL}

Being non-linear nature of railway wheelset model, it is difficult to estimate the wheelset dynamics with ordinary estimation techniques. Therefore Extended Kalman filter is used to estimate wheelset dynamics and contact force in all adhesion conditions. Kalman filter utilizes measurements associated to the state and error covariance matrices to produce a gain known as Kalman gain. Figure 3 shows the block diagram of Kalman filter with generic scheme.

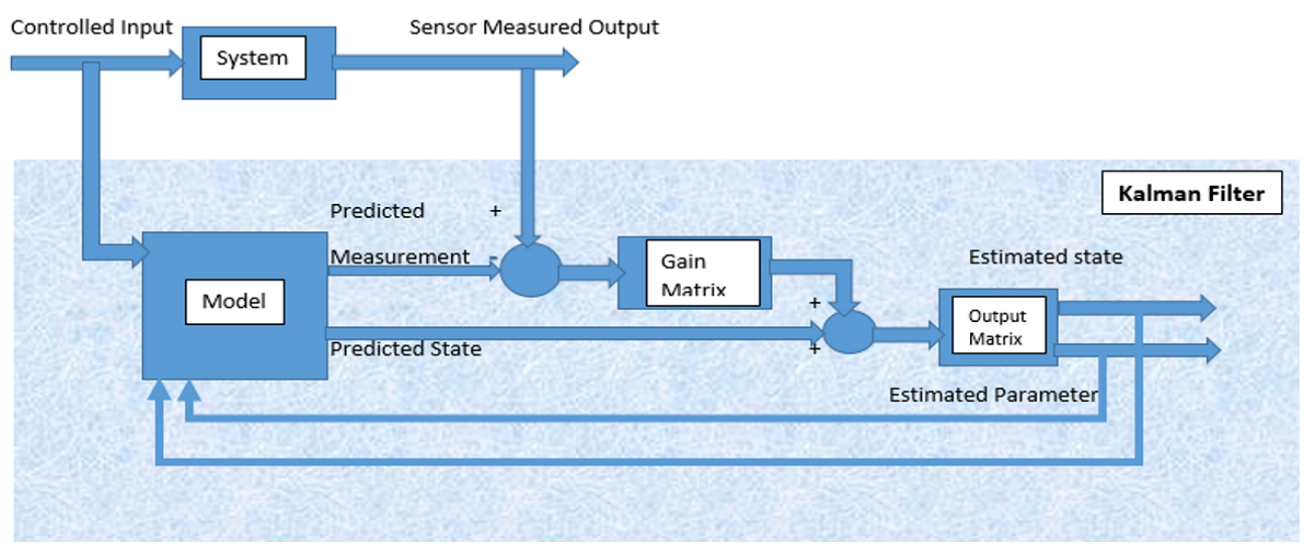

Figure 3. Block diagram of the Kalman filter with generic scheme.

Extended Kalman filter (the extension form of Kalman filter) linearizes the current mean and covariance by assessing Jacobian matrices and their partial derivatives (Ngigi et al., 2012)

From non-linear model of railway wheelset, single equation (18) in matrix form is furnished after putting the values of $F_{x R}, F_{x L}, F_{y R}$ and $F_{y L}$ in equations (13) and (14). 


$$
\left[\begin{array}{c}
y^{\prime} \\
\Psi^{\prime} \\
y^{\prime \prime} \\
\Psi^{\prime \prime}
\end{array}\right]=\left[\begin{array}{cccc}
0 & 0 & 1 & 0 \\
0 & 0 & 0 & 1 \\
0 & \frac{1}{m_{w}}\left(\frac{F_{R}}{\gamma_{R}}+\frac{F_{L}}{\gamma_{L}}\right) & -\frac{1}{m_{w} v}\left(\frac{F_{R}}{\gamma_{R}}+\frac{F_{L}}{\gamma_{L}}\right) & 0 \\
-\frac{L_{g} \lambda_{w}}{I_{w} r_{0}}\left(\frac{F_{R}}{\gamma_{R}}+\frac{F_{L}}{\gamma_{L}}\right) & -\frac{k_{w}}{I_{w}} & 0 & -\frac{L_{g}{ }^{2}}{I_{w} v}\left(\frac{F_{R}}{\gamma_{R}}+\frac{F_{L}}{\gamma_{L}}\right)
\end{array}\right]\left[\begin{array}{c}
y \\
\Psi \\
y^{\prime} \\
\Psi^{\prime}
\end{array}\right]+\left[\begin{array}{c}
0 \\
0 \\
0 \\
\frac{L_{g}}{I_{w} r_{0}}\left(\frac{F_{R}}{\gamma_{R}}+\frac{F_{L}}{\gamma_{L}}\right)
\end{array}\right] y_{t}
$$

If left and right wheel creep are same $\left(\gamma_{R}=\gamma_{\mathrm{L}}=\gamma\right.$ and $\left.F_{R}=F_{L}=F\right)$ then

$$
\left[\begin{array}{c}
y^{\prime} \\
\Psi^{\prime} \\
y^{\prime \prime} \\
\Psi^{\prime \prime}
\end{array}\right]=\left[\begin{array}{cccc}
0 & 0 & 1 & 0 \\
0 & 0 & 0 & 1 \\
0 & \frac{2}{m_{w}} \frac{F}{\gamma} & -\frac{2}{m_{w} v} \frac{F}{\gamma} & 0 \\
-\frac{2 L_{g} \lambda_{w}}{I_{w} r_{0}} \frac{F}{\gamma} & -\frac{k_{w}}{I_{w}} & 0 & -\frac{2 L_{g}^{2}}{I_{w} v} \frac{F}{\gamma}
\end{array}\right]\left[\begin{array}{c}
y \\
\Psi \\
y^{\prime} \\
\Psi^{\prime}
\end{array}\right]+\left[\begin{array}{c}
0 \\
0 \\
0 \\
\frac{2 L_{g}}{I_{w} r_{0}} \frac{F}{\gamma}
\end{array}\right] y_{t}
$$

Here are state variables of wheelset model i.e $y^{\prime}$ (lateral velocity), $\Psi^{\prime}$ 'Yaw rate) $\gamma$ (Creep or slip), $\mathrm{U}$ (friction coefficient) and $F$ (Creep force) taken for EKF algorithm. Lateral acceleration $(y$ ') and yaw rate $(\Psi$ ') can be measured along noise with accelerometer and gyroscope. From equation (19):

$$
\begin{gathered}
y^{\prime \prime}=\left(y^{\prime}\right)^{\prime}=\frac{2}{m_{w}}\left(\Psi \frac{F}{\gamma}-\frac{y^{\prime}}{\mathrm{v}} \frac{F}{\gamma}\right) \\
\Psi^{\prime \prime}=\left(\Psi^{\prime}\right)^{\prime}=\frac{1}{I_{w}}\left(\frac{2 y_{t} L_{g}}{r_{0}} \frac{F}{\gamma}-\frac{2 y L_{g} \lambda_{w}}{r_{0}} \frac{F}{\gamma}-\frac{2 \Psi^{\prime} L_{g}{ }^{2}}{v} \frac{F}{\gamma}-K_{w} \Psi\right) \\
\gamma=\sqrt{\left(\frac{L_{g} \Psi^{\prime}}{v}+\frac{\lambda_{w}\left(\mathrm{y}-y_{t}\right)}{r_{0}}\right)^{2}+\left(\frac{y^{\prime}}{v}-\Psi\right)^{2}} \\
\left.F=\frac{2 \mathrm{NU}}{U_{k}=u_{0}\left[(1-A) e^{(-B \gamma \mathrm{v})}+A\right]} \frac{\mathrm{k}_{A}}{1+\left(\mathrm{k}_{A}\right)^{2}}+\arctan \left(\mathrm{k}_{S}\right)\right]
\end{gathered}
$$


Now it is required to discretize equations (20)-(24) by using Forward Euler (FE) method in order to design Extended Kalman filter for estimation.

$$
\begin{aligned}
& y_{k}^{\prime}=y_{k-1}^{\prime}+\frac{2 \tau}{m_{w}}\left(\Psi \frac{F_{k-1}}{\gamma_{k-1}}-\frac{y_{k-1}^{\prime}}{\mathrm{v}} \frac{F_{k-1}}{\gamma_{k-1}}\right) \\
& \Psi_{k}^{\prime}=\Psi_{k-1}^{\prime}+\frac{\tau}{I_{w}}\left(\frac{2 \mathrm{y}_{t} \mathrm{~L}_{g}}{r_{0}} \frac{F_{k-1}}{\gamma_{k-1}}-\frac{2 \mathrm{yL}_{g} \lambda_{w}}{r_{0}} \frac{F_{k-1}}{\gamma_{k-1}}-\frac{2 \Psi_{k-1}^{\prime} \mathrm{L}_{g}{ }^{2}}{r_{0}} \frac{F_{k-1}}{\gamma_{k-1}}-K_{w} \Psi\right) \\
& \gamma_{k}=\sqrt{\left(\frac{L_{g} \Psi_{k-1}^{\prime}}{v}+\frac{\lambda_{w}\left(\mathrm{y}-y_{t}\right)}{r_{0}}\right)^{2}+\left(\frac{y_{k-1}^{\prime}}{v}-\Psi\right)^{2}} \\
& U_{k}=u_{0}\left[(1-A) e^{\left(-B \gamma_{k-1} v\right)}+A\right] \\
& \left.F_{k}=\frac{2 \mathrm{NU}_{k-1}}{1+\left(\mathrm{k}_{A} \frac{2}{3} \frac{a^{2} b \mathrm{c}}{\mathrm{NU}_{k-1}} \gamma_{k-1}\right)^{2}}+\arctan \left(\mathrm{k}_{S} \frac{2}{3} \frac{a^{2} b \mathrm{c}}{\mathrm{NU}_{k-1}} \gamma_{k-1}\right)\right]
\end{aligned}
$$

As the Extended Kalman filter uses a 2 step predictor-corrector algorithm (Welch \& Bishop, 2001). The predictor step is given by

$$
\begin{gathered}
\hat{x}_{k}^{-}=f\left(\hat{x}_{k-1}, u_{k}, k\right) \\
P_{k}^{-}=F_{k-1} P_{k-1} F_{k-1}^{T}+Q_{k}
\end{gathered}
$$

And the equations of corrector step are,

$$
\begin{gathered}
K_{k}=P_{k}^{-} H_{k}^{T}\left(H_{k} P_{k}^{-} H_{k}^{T}+R_{k}\right)^{-1} \\
\hat{x}_{k}=\hat{x}_{k}^{-}+K_{k}\left(\tilde{y}_{k}-h\left(x_{k}^{\wedge-}, u_{k}, k\right)\right) \\
P_{k}=\left(I-K_{k} H_{k}\right) P_{k}^{-}
\end{gathered}
$$

Where $\mathrm{f}$ and $\mathrm{h}$ are non-linear functions relating to process and measurement states, while: 


$$
F_{k}=\frac{\partial f}{\partial x} \mid \hat{x}_{k}, u_{k}, k \text { and } H_{k}=\frac{\partial h}{\partial x} \mid \hat{x}_{k}, u_{k}, k
$$

Nomenclature of EKF algorithm is given in below table.

Table 2. Nomenclature of EKF algorithm.

\begin{tabular}{|l|l|}
\hline Symbol & Description \\
\hline $\mathbf{X}-\mathrm{k}$ & discretized a-priori estimated process \\
$\mathbf{x} \mathrm{k}$ & discretized a-postriori estimated process \\
\hline $\mathrm{Pk}-$ & a-priori estimate of the covariance of process error \\
\hline $\mathrm{Pk}$ & estimate of the covariance of measurement error \\
\hline $\mathrm{Fk}$ & Jacobian matrix of process \\
\hline $\mathrm{Hk}$ & Jacobian matrix of measurement \\
\hline $\mathrm{Qk}$ & process noise covariance \\
\hline $\mathrm{Rk}$ & measurement noise covariance \\
\hline $\mathrm{Kk}$ & Kalman gain \\
\hline$\tilde{y} \mathrm{k}$ & measured output \\
\hline
\end{tabular}

The Jacobean matrix of process matrix:

$$
\begin{aligned}
& x_{k}=\left[\begin{array}{c}
y_{k}^{\prime} \\
\Psi_{k}^{\prime} \\
\gamma_{k} \\
U_{k} \\
F_{k}
\end{array}\right] \text { is } \\
& F_{k}=\left[\begin{array}{lllll}
\frac{\partial y_{k}^{\prime}}{\partial y_{k}^{\prime}} & \frac{\partial y_{k}^{\prime}}{\partial \psi_{k}^{\prime}} & \frac{\partial y_{k}^{\prime}}{\partial \gamma_{k}} & \frac{\partial y_{k}^{\prime}}{\partial U_{k}} & \frac{\partial y_{k}^{\prime}}{\partial F_{k}} \\
\frac{\partial \psi_{k}^{\prime}}{\partial y_{k}^{\prime}} & \frac{\partial \psi_{k}^{\prime}}{\partial \psi_{k}^{\prime}} & \frac{\partial \psi_{k}^{\prime}}{\partial \gamma_{k}} & \frac{\partial \psi_{k}^{\prime}}{\partial U_{k}} & \frac{\partial \psi_{k}^{\prime}}{\partial F_{k}} \\
\frac{\partial \gamma_{k}}{\partial y_{k}^{\prime}} & \frac{\partial \gamma_{k}}{\partial \psi_{k}^{\prime}} & \frac{\partial \gamma_{k}}{\partial \gamma_{k}} & \frac{\partial \gamma_{k}}{\partial U_{k}} & \frac{\partial \gamma_{k}}{\partial F_{k}} \\
\frac{\partial U_{k}}{\partial y_{k}^{\prime}} & \frac{\partial U_{k}}{\partial \psi_{k}^{\prime}} & \frac{\partial U_{k}}{\partial \gamma_{k}} & \frac{\partial U_{k}}{\partial U_{k}} & \frac{\partial U_{k}}{\partial F_{k}} \\
\frac{\partial F_{k}}{\partial y_{k}^{\prime}} & \frac{\partial F_{k}}{\partial \psi_{k}^{\prime}} & \frac{\partial F_{k}}{\partial \gamma_{k}} & \frac{\partial F_{k}}{\partial U_{k}} & \frac{\partial F_{k}}{\partial F_{k}}
\end{array}\right]
\end{aligned}
$$


And the Jacobian matrix of measurement matrix $m_{k}=\left[\begin{array}{c}y_{k}^{\prime \prime} \\ \Psi_{k}^{\prime}\end{array}\right]$ is

$$
H_{k}=\left[\begin{array}{lllll}
\frac{\partial y_{k}^{\prime \prime}}{\partial y_{k}^{\prime}} & \frac{\partial y_{k}^{\prime \prime}}{\partial \Psi_{k}^{\prime}} & \frac{\partial y_{k}^{\prime \prime}}{\partial \gamma_{k}} & \frac{\partial y_{k}^{\prime \prime}}{\partial U_{k}} & \frac{\partial y_{k}^{\prime \prime}}{\partial F_{k}} \\
\frac{\partial \Psi_{k}^{\prime}}{\partial y_{k}^{\prime}} & \frac{\partial \Psi_{k}^{\prime}}{\partial \Psi_{k}^{\prime}} & \frac{\partial \Psi_{k}^{\prime}}{\partial \gamma_{k}} & \frac{\partial \Psi_{k}^{\prime}}{\partial U_{k}} & \frac{\partial \Psi_{k}^{\prime}}{\partial F_{k}}
\end{array}\right]
$$

\section{SIMULATION RESULTS}

The simulation models of non-linear railway wheelset and EKF are developed in Simulink/ MATLAB and are simulated 50 microseconds step size. As the vehicle is kept on constant velocity i.e. motor torque is applied zero, only random track disturbance of $\pm 7 \mathrm{~mm}$ magnitude in lateral direction is applied as input to the model for exciting lateral dynamics. Curves of Figure 2 are tuned with Polach parameters $k_{A}, k_{S}, u_{0}, A$ and $B$. Table 3 contains the values which are used to tune these creep curves. Along with Kalman gain and Jacobian matrices, the other EKF tuning parameters are measurement noise covariance of inertial sensors and process noise covariance for entire range of track conditions which are set in equation (37)-(40). The measurement noise covariance matrix in equation (37) is calculated by adding noise power for accelerometer and gyro sensor, while the process noise matrices of equations (38)-(40) are calculated based on fine tuning of results.

$$
\begin{gathered}
R=\left[1 \times 10^{-7} 1 \times 10^{-13}\right] \\
Q 1=\left[5 \times 10^{-14} 1 \times 10^{-14} 1 \times 10^{-14} 1 \times 10^{-14} 1 \times 10^{-14}\right] \text { for dry condition } \\
Q 2=\left[0.5 \times 10^{-12} 9 \times 10^{-17} 1 \times 10^{-12} 1 \times 10^{-12} 1 \times 10^{-12}\right] \text { for wet condition } \\
Q 3=Q 4=\left[1 \times 10^{-13} 9 \times 10^{-17} 1 \times 10^{-12} 1 \times 10^{-12} 1 \times 10^{-12}\right] \text { for poor and worst condition }
\end{gathered}
$$

Table 3. Polach parameters.

\begin{tabular}{|c|c|c|c|c|}
\hline Parameter & Dry condition & Wet condition & Poor condition & Worst condition \\
\hline KA & 1 & 1 & 1 & 1 \\
\hline KS & 1 & 1 & 1 & 1 \\
\hline U0 & 0.46 & 0.3 & 0.2 & 0.1 \\
\hline A & 0.4 & 0.4 & 0.1 & 0.1 \\
\hline B & 0.6 & 0.2 & 0.2 & 0.2 \\
\hline
\end{tabular}


Following tests are performed on wheelset with EKF algorithm.

(i) Dry condition, (ii) Wet condition, (iii) Poor condition, (iv) Worst condition and (v) Transition from dry condition to worst condition.

\subsection{DRY CONDITION TEST}

The lateral velocity and yaw rate of wheelset as well as creep and creep force are computed along with error on dry condition curve (Dry curve of Figure 2) and shown in Figure 4 to 7.

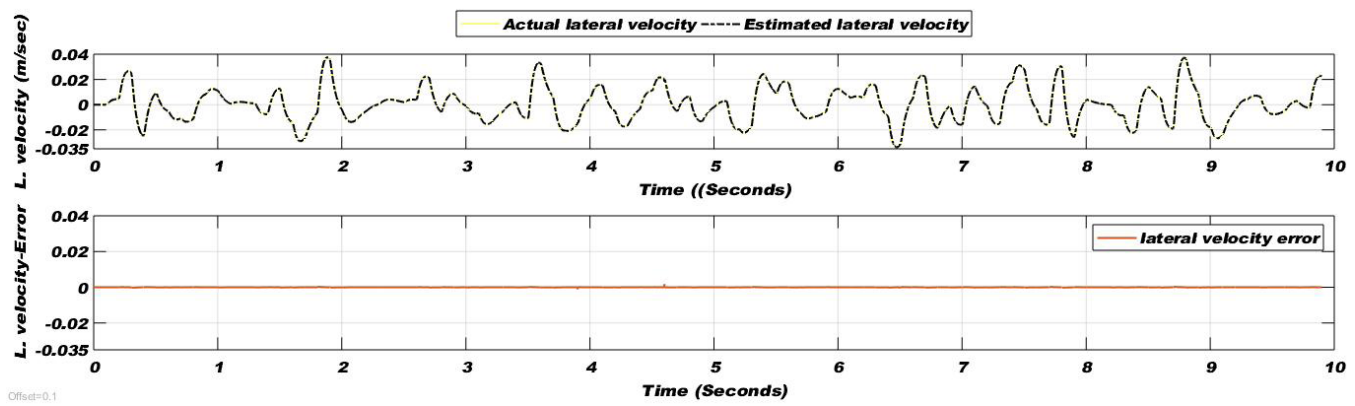

Figure 4. lateral velocity comparison (top) and Error (bottom) for dry condition of wheel-rail interface.
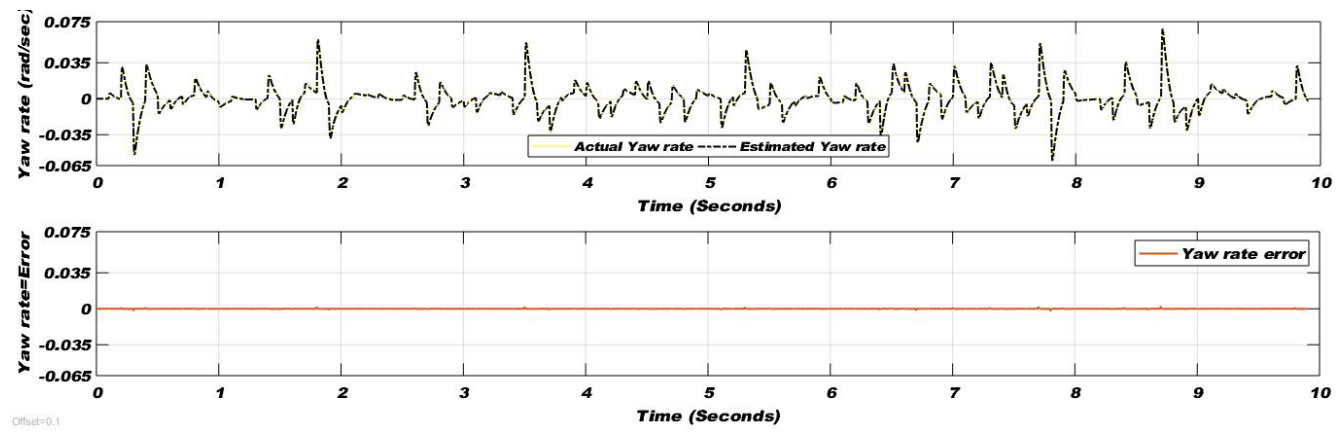

Figure 5. Yaw rate comparison (top) and Error (bottom) for dry condition of wheel-rail interface.
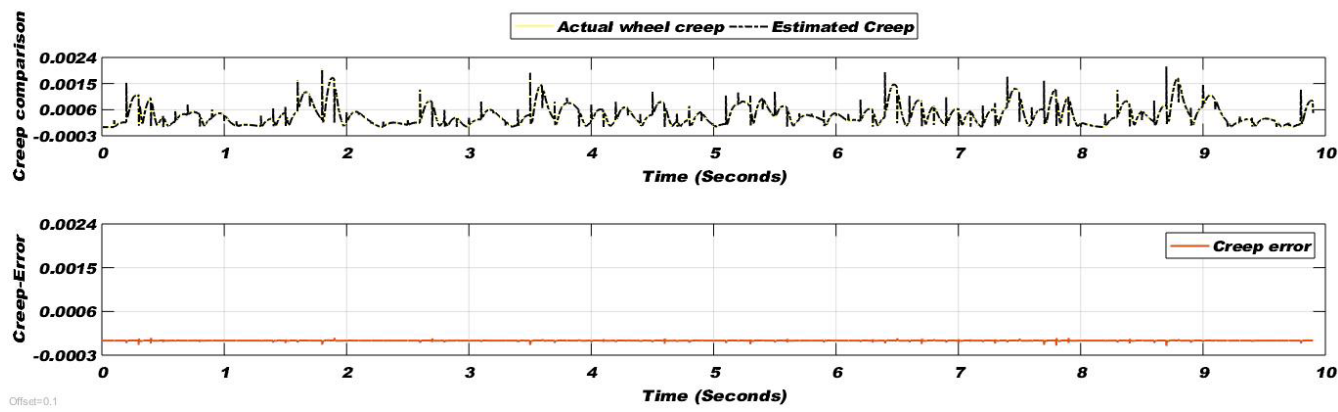

Figure 6. Creep comparison (top) and Error (bottom) for dry condition of wheel-rail interface. 

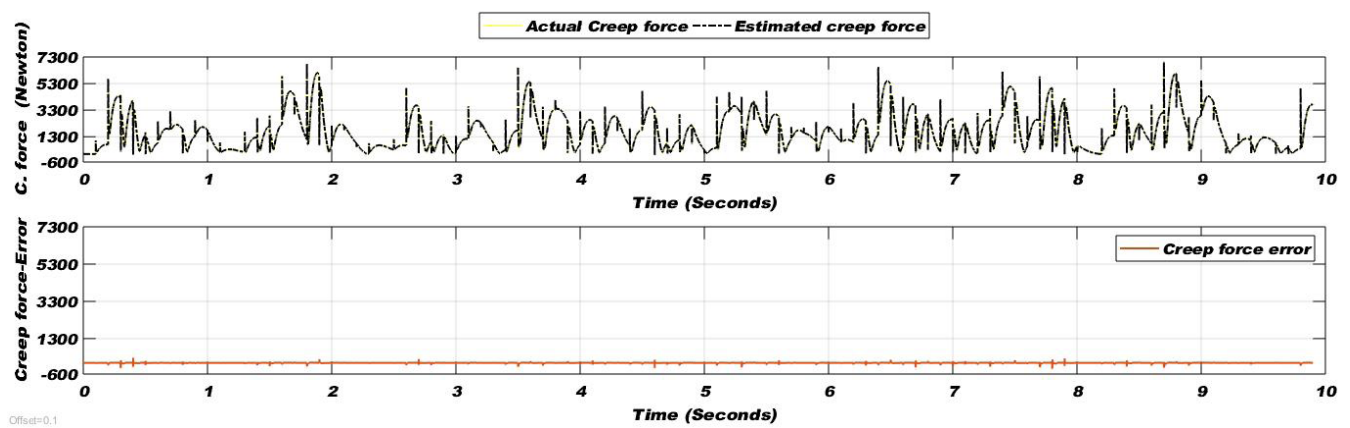

Figure 7. Creep force comparison (top) and Error (bottom) for dry condition of wheel-rail interface.

\subsection{WET CONDITION TEST}

The lateral velocity and yaw rate of wheelset as well as creep and creep force are computed along with error on wet track condition curve (Wet curve of Figure 2) and shown in Figure 8 to 11 .
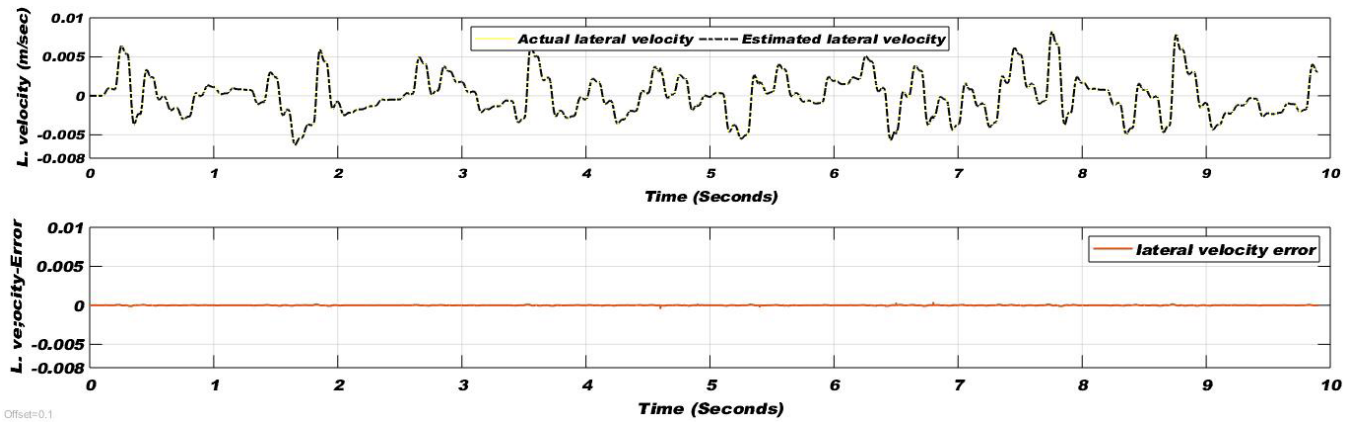

Figure 8. Lateral velocity comparison (top) and Error (bottom) for wet condition of wheel-rail interface.
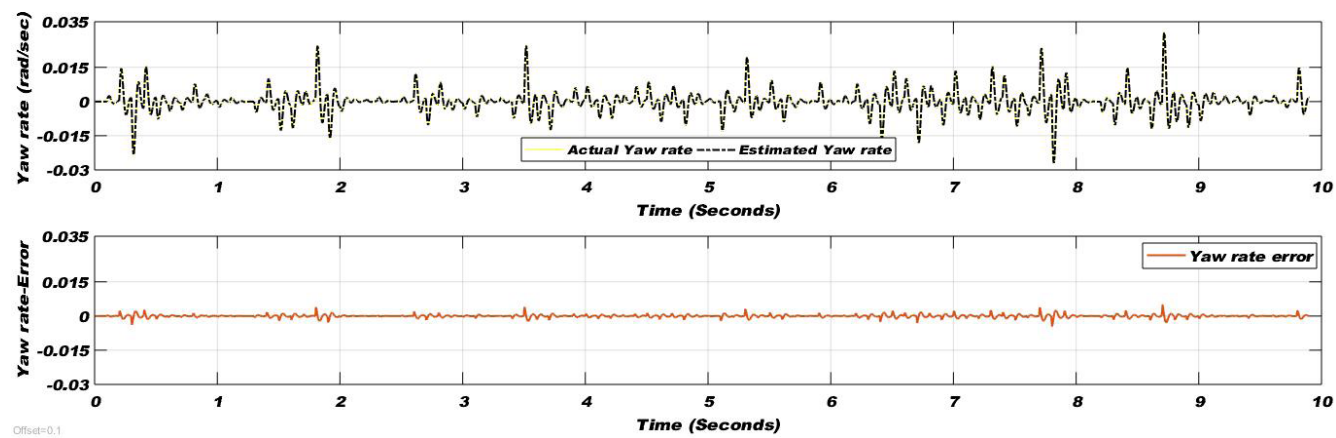

Figure 9. Yaw rate comparison (top) and Error (bottom) for wet condition of wheel-rail interface. 

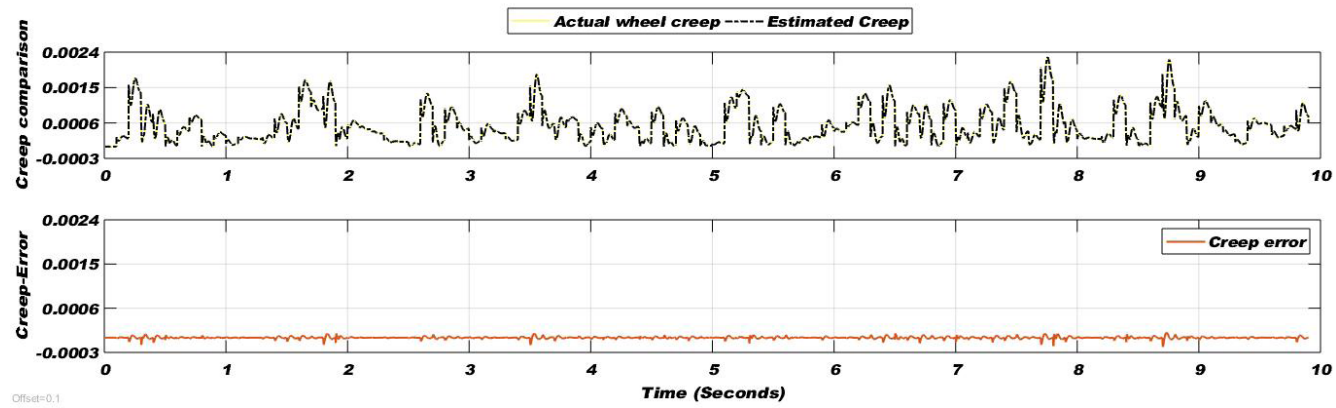

Figure 10. Creep comparison (top) and Error (bottom) for wet condition of wheel-rail interface.
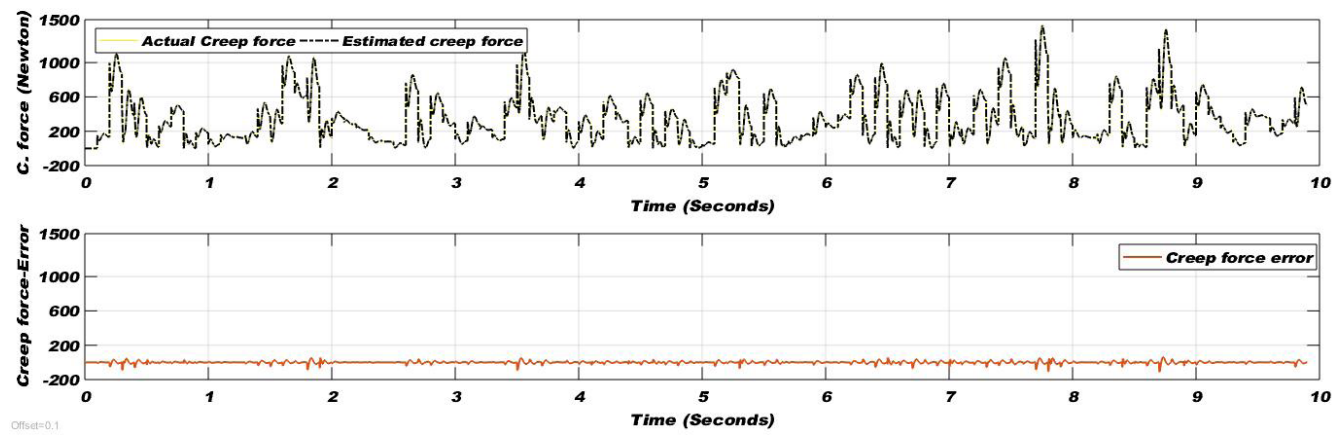

Figure 11. Creep force comparison (top) and Error (bottom) for wet condition of wheel-rail interface.

\subsection{POOR CONDITION TEST}

The lateral velocity and yaw rate of wheelset as well as creep and creep force are computed along with error on poor track condition curve (Poor curve of Figure 2) and shown in Figure 12 to 15 .
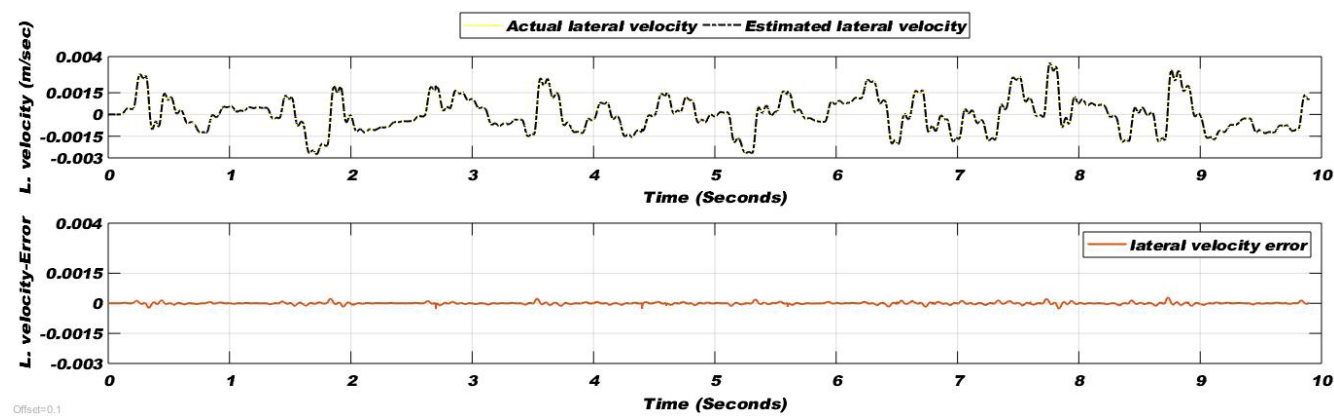

Figure 12. Lateral velocity comparison (top) and Error (bottom) for poor condition of wheel-rail interface. 

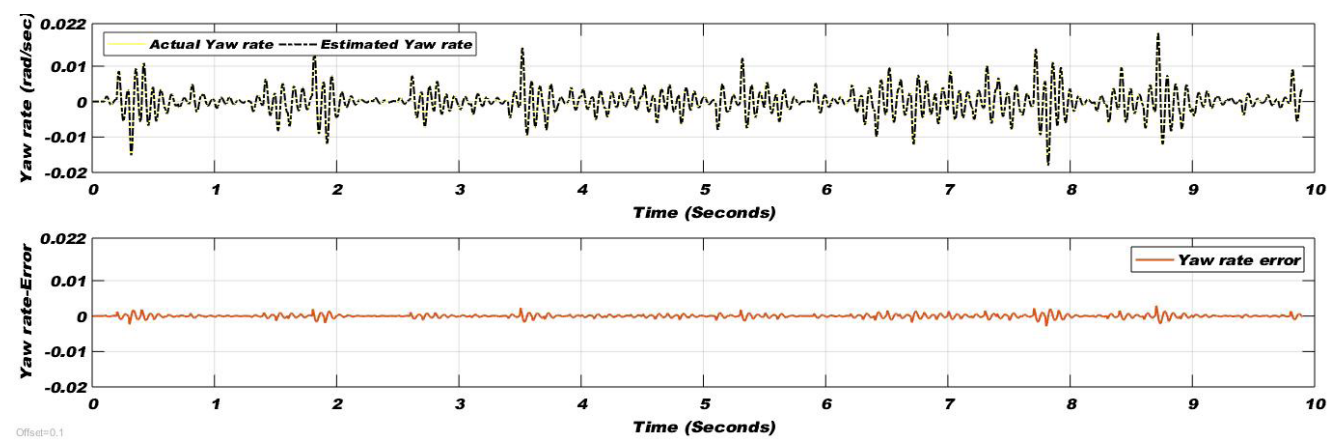

Figure 13. Yaw rate comparison (top) and Error (bottom) for poor condition of wheel-rail interface.
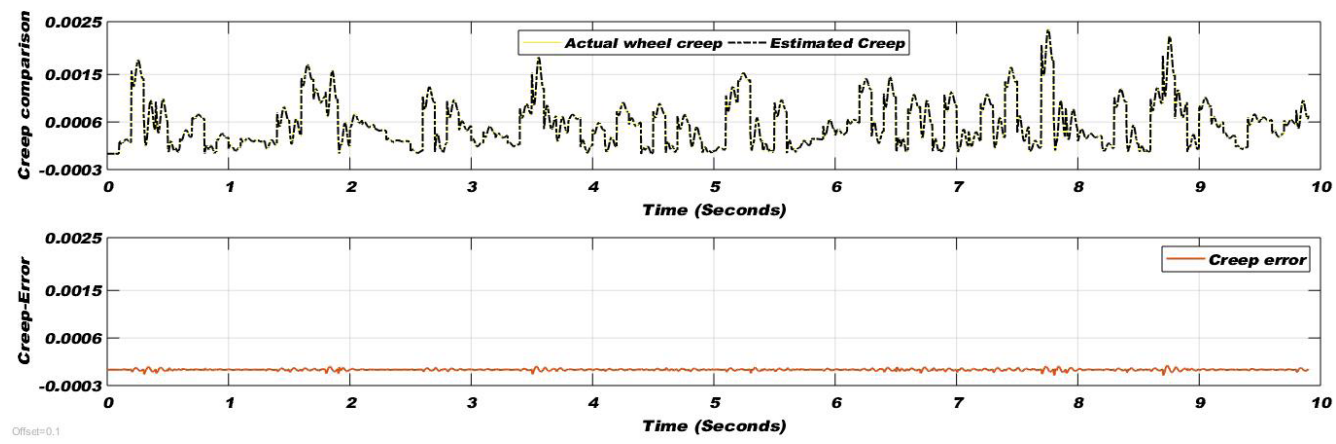

Figure 14. Creep comparison (top) and Error (bottom) for poor condition of wheel-rail interface.
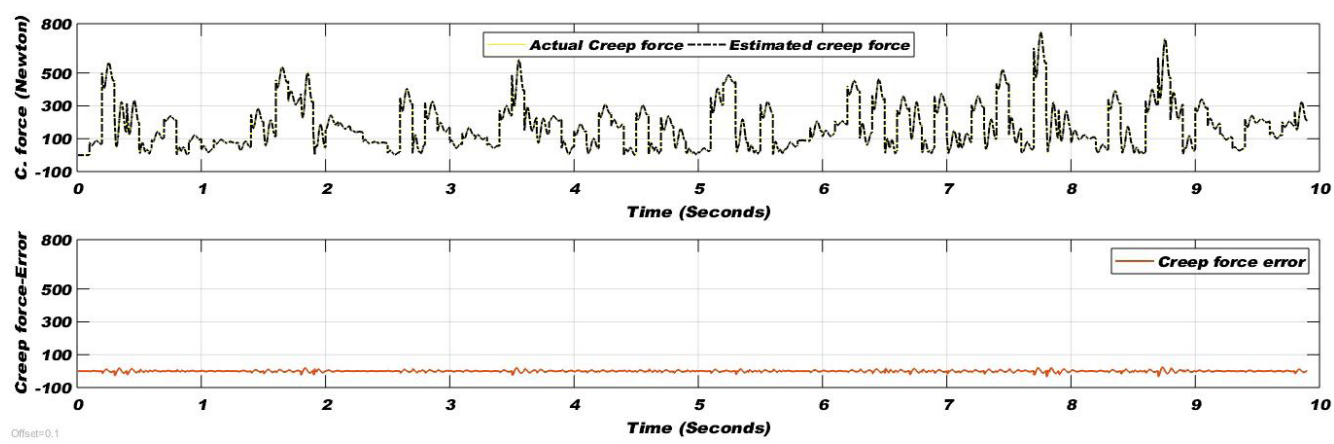

Figure 15. Creep force comparison (top) and Error (bottom) for poor condition of wheel-rail interface.

\subsection{WORST CONDITION TEST}

The lateral velocity and yaw rate of wheelset as well as creep and creep force are computed along with error on worst track condition curve (Worst curve of Figure 2) and shown in Figure 16 to 19. 

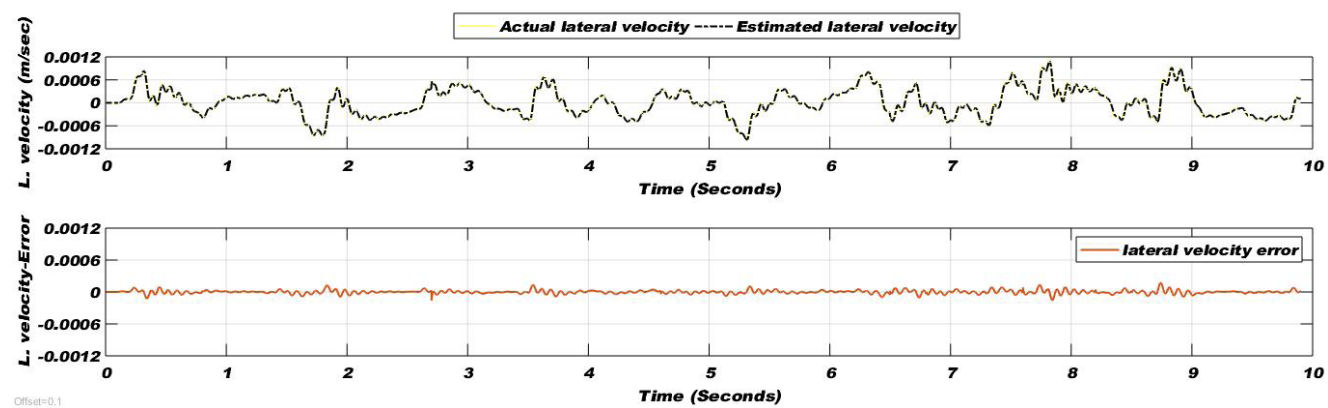

Figure 16. Lateral velocity comparison (top) and Error (bottom) for worst condition of wheel-rail interface.
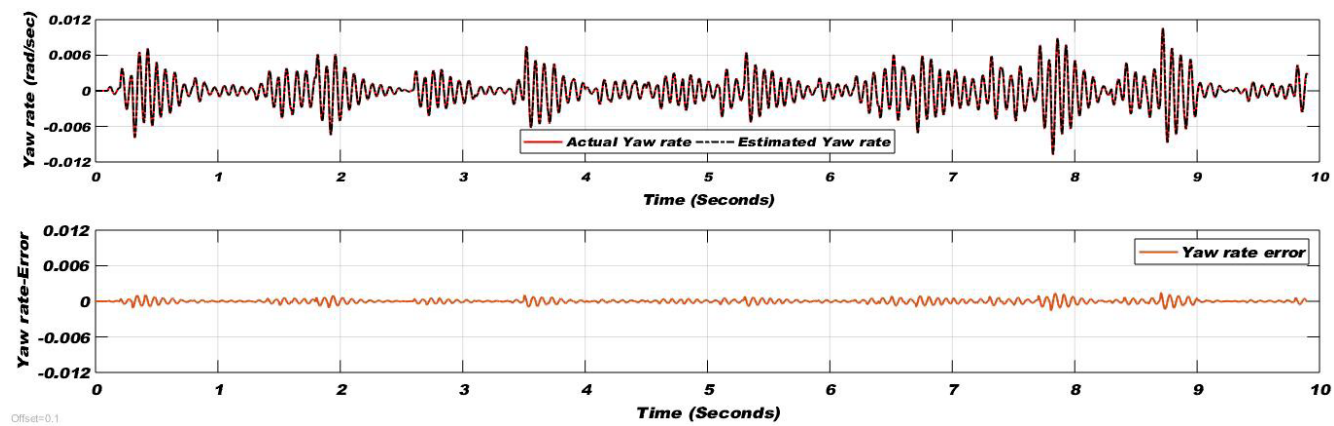

Figure 17. Yaw rate comparison (top) and Error (bottom) for worst condition of wheel-rail interface.
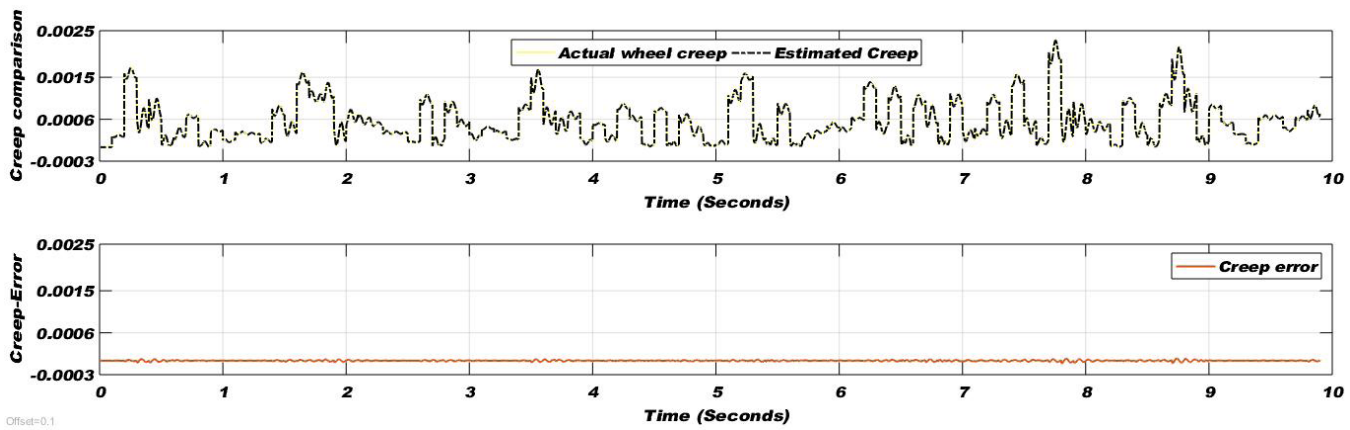

Figure 18. Creep comparison (top) and Error (bottom) for worst condition of wheel-rail interface.
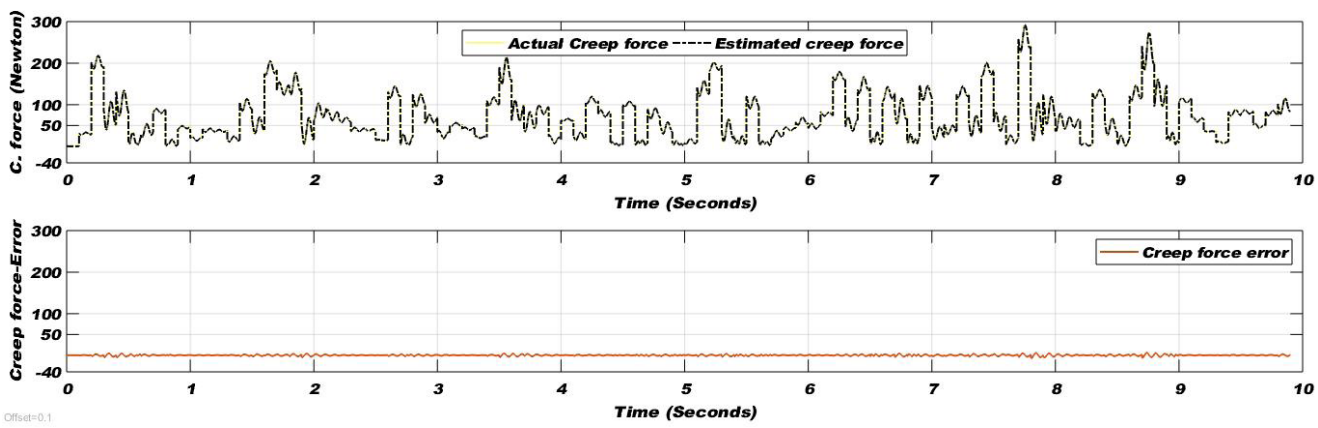

Figure 19. Creep force comparison (top) and Error (bottom) for worst condition of wheel-rail interface. 


\subsection{TRANSITION TEST FROM DRY CONDITION TO WORST CONDITION}

The lateral velocity and yaw rate of wheelset as well as creep and creep force are computed along with error on all adhesion condition curves (Dry to worst curves of Figure 2) and shown in Figure 20 to 23. During simulation adhesion condition changed at every 2 seconds from dry to worst adhesion conditions in 8 seconds of simulation time and then the condition again changed from worst to wet. The graphs show the changings of adhesion conditions and match estimated results with actual results.
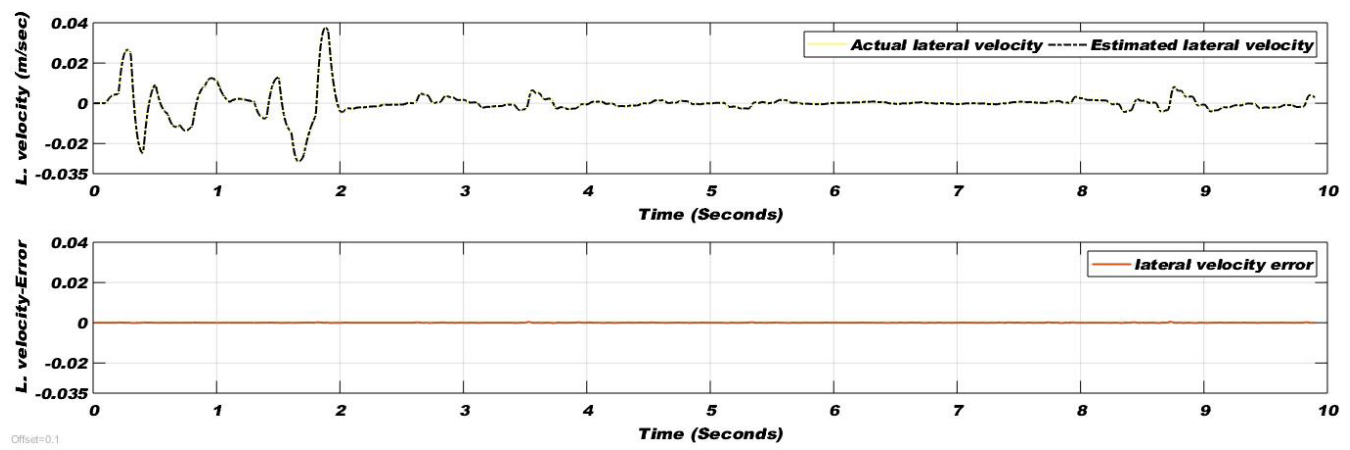

Figure 20. Lateral velocity comparison (top) and Error (bottom) for all track conditions of wheel-rail interface.
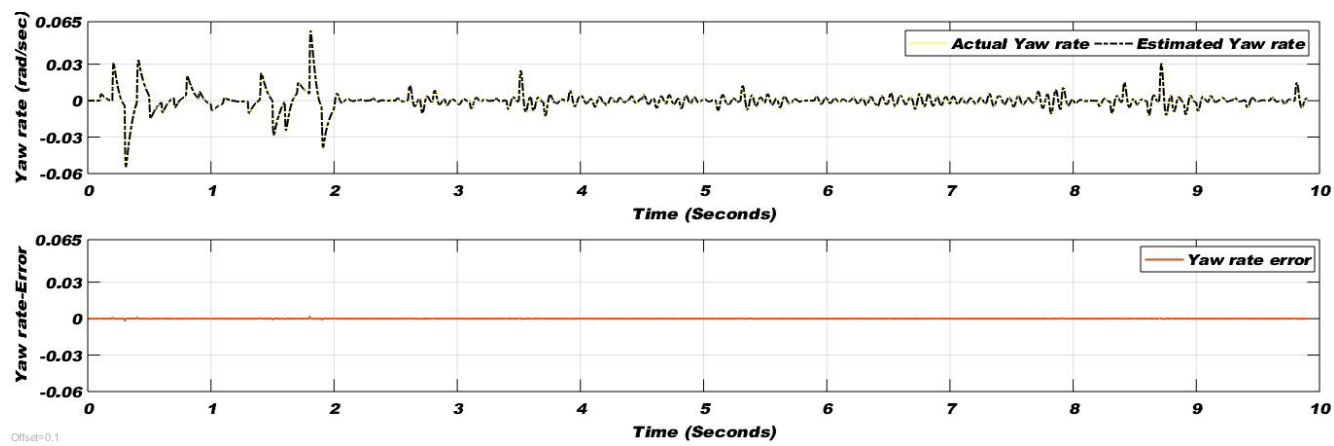

Figure 21. Yaw rate comparison (top) and Error (bottom) for all adhesion condition of wheel-rail interface.
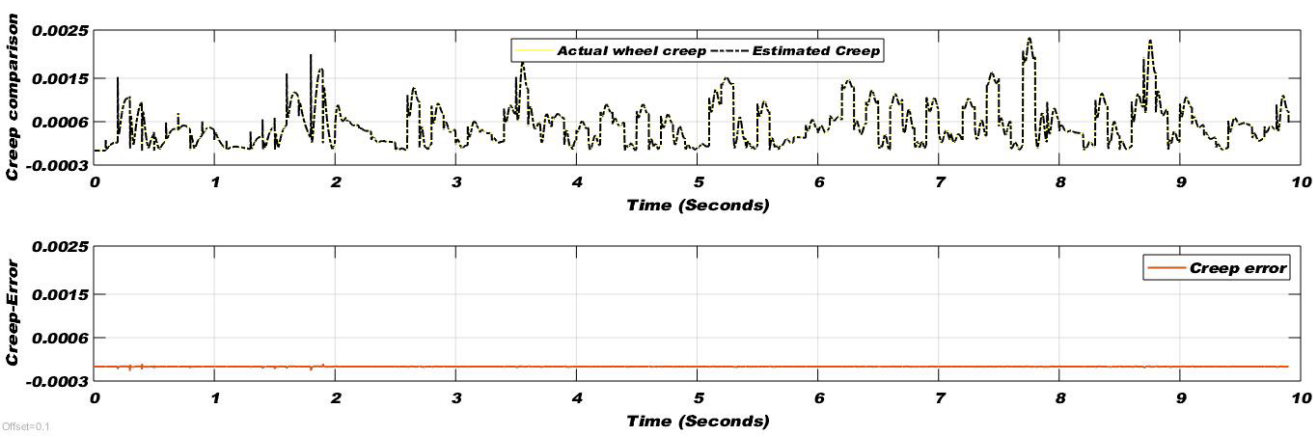

Figure 22. Creep comparison (top) and Error (bottom) for all adhesion condition of wheel-rail interface. 

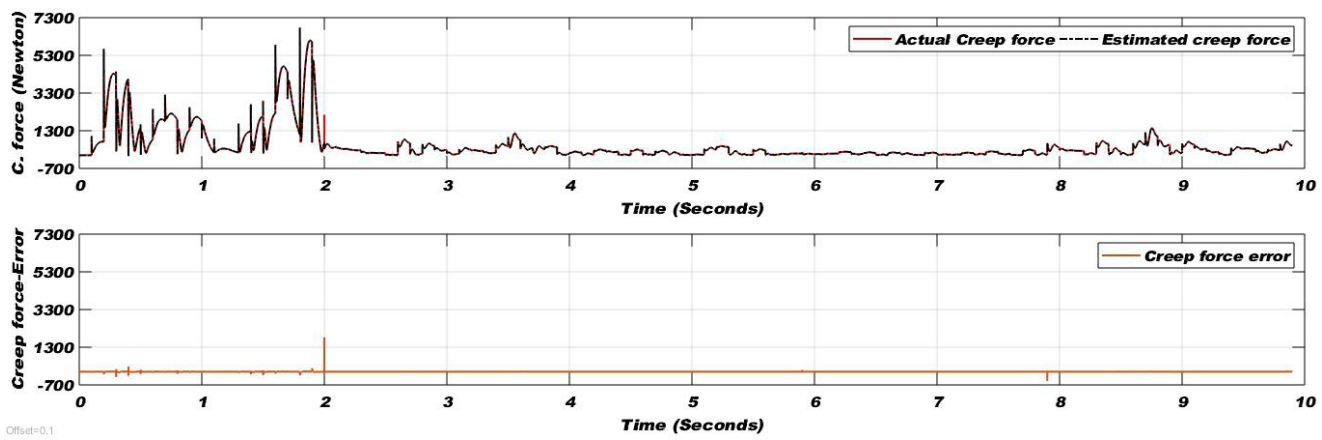

Figure 23. Creep force comparison (top) and Error (bottom) for all adhesion condition of wheel-rail interface.

\subsection{ERROR ANALYSIS}

It is shown from Figure 4 to 23 that the Extended Kalman filter is a valid estimation technique to estimate wheelset dynamics with authenticity. However, estimated creep force error in Figure 23 became high for few moments during simulation (a spike seen at 2 seconds) due to sudden change of adhesion condition from dry to wet.

Overall, EKF estimates the wheelset dynamics perfectly for dry, wet, poor and worst adhesion conditions and can be used for condition monitoring of rolling stock.

\section{CONCLUSION}

As wheel-rail contact force is complex and non-linear function of slip and affected with other vehicle parameters, therefore it is difficult to estimate by simple estimating techniques. In this paper, the Extended Kalman filter is used to estimated lateral velocity and yaw rate of railway wheelset as well as creep and creep force of wheel-rail interface and validated through Simulink/MATLAB. EKF estimates not only wheelset dynamics for dry, wet, poor and worst adhesion conditions but perfectly estimates for transition of all track conditions during simulation.

Further, research is going to estimate wheel-rail dynamics in traction and braking modes, also work is going on to implement the simulation work on FPGA platform. 


\section{ACKNOWLEDGEMENT}

The authors would like to acknowledge "Condition Monitoring System Lab at Mehran University of Engineering and Technology, Jamshoro, part of NCRA project of Higher Education Commission Pakistan, for supporting their work.

\section{REFERENCES}

Anyakwo, A., Pislaru, G., \& Ball, A. (2012). A new method for modelling and simulation of the dynamic behaviour of the wheel-rail contact. International fournal of Automation and Computing, 9(3), 237-247. https://doi.org/10.1007/s11633-012-0640-6

Charles, G., Goodall, R., \& Dixon, R. (2008). Model-based condition monitoring at the wheel-rail interface. Vehicle System Dynamics, 46(SUPPL.1), 415-430. https://doi. org/10.1080/00423110801979259.

Hubbard, P. D., Ward, G., Dixon, R., \& Goodall, R. (2013a). Real time detection of low adhesion in the wheel/rail contact. Proceedings of the Institution of Mechanical Engineers, Part F: Fournal of Rail and Rapid Transit, 227(6), 623-634. https://doi. org/10.1177/0954409713503634

Hubbard, P. D., Ward, C., Dixon, R., \& Goodall, R. (2013b). Verification of modelbased adhesion estimation in the wheel-rail interface. Chemical Engineering Transactions, 33, 757-762. https://doi.org/10.3303/CET1333127

Hussain, I. (2012). Multiple Model Based Real Time Estimation of Wheel-Rail Contact Conditions (PhD thesis). University of Salford. http://usir.salford.ac.uk/id/eprint/38094/

Hussain, I., \& Mei, T. X. (2010). Multi Kalman filtering approach for estimation of wheel-rail contact conditions. In UKACG International Conference on CONTROL 2010. https://doi.org/10.1049/ic.2010.0326 
Hussain, I., \& Mei, T. X. (2011). Identification of the wheel-rail contact condition for traction and braking control. Proceedings of the 22nd International Symposium on Dynamics of Vehicles on Roads and Tracks, Manchester, United Kingdom, pp. 14-19. https://www. researchgate.net/publication/261672525_Identification_of_the_Wheel-Rail_ Contact_Conditions_for_Traction_and_Braking_control

Hussain, I., Mei, T. X., \& Jones, A. H. (2009). Modeling and estimation of non-linear wheel-rail contact mechanics. In 20th International Conference on Systems Engineering (ICSE2009), 219-223. https://www.researchgate.net/publication/261633475_ Modeling_and_Estimation_of_Non-linear_Wheel-Rail_Contact_Mechanics

Hussain, I., Mei, T. X., \& Ritchings, R. T. (2013). Estimation of wheel-rail contact conditions and adhesion using the multiple model approach. Vehicle System Dynamics, 51(1), 32-53. https://doi.org/10.1080/00423114.2012.708759

Mei, T., Yu, J., \& Wilson, D. (2008). A mechatronic approach for anti-slip control in railway traction. IFAC Proceedings Volumes, 41(2), 8275-8280. https://doi. org/10.3182/20080706-5-KR-1001.01399

Melnik, R., \& Koziak, S. (2017). Rail vehicle suspension condition monitoring approach and implementation. Fournal of Vibroengineering, 19(1), 487-501. https:// doi.org/10.21595/jve.2016.17072

Ngigi, R. W., Pislaru, G., Ball, A., \& Gu, F. (2012). Modern techniques for condition monitoring of railway vehicle dynamics. Fournal of Physics: Conference Series, 364(1). https://iopscience.iop.org/article/10.1088/1742-6596/364/1/012016/meta

Polach, O. (2005). Creep forces in simulations of traction vehicles running on adhesion limit. Wear, 258(7-8), 992-1000. https://doi.org/10.1016/j.wear.2004.03.046

Radionov, I. A., \& Mushenko, A. S. (2015). The method of estimation of adhesion at "wheel-railway" contact point. In 2015 International Siberian Conference on Control and Communications (SIBCON), pp. 1-5. https:/ / doi.org/10.1109/SIBCON.2015.7147156

Simon, I. (2006). Handbook of Railway Vehicle Dynamics, Handbook of Railway Vehicle Dynamics. CRC Press. 
Strano, S., \& Terzo, M. (2018). On the real-time estimation of the wheel-rail contact force by means of a new nonlinear estimator design model. Mechanical Systems and Signal Processing, 105, pp. 391-403. https://doi.org/10.1016/j.ymssp.2017.12.024

Sun, Y. Q., Gole, G., \& Spiryagin, M. (2015). Monitoring vertical wheel-rail contact forces based on freight wagon inverse modelling. Advances in Mechanical Engineering, 7(5), 1-11. https://www.researchgate.net/publication/277910673_Monitoring_ vertical_wheel-rail_contact_forces_based_on_freight_wagon_inverse_modelling

Wang, S., Xiao, J., Huang, J., \& Sheng, H. (2016). Locomotive wheel slip detection based on multi-rate state identification of motor load torque. Fournal of the Franklin Institute, 353(2), 521-540. https://doi.org/10.1016/j.jfranklin.2015.11.012

Ward, G. P., Goodall, R. M., \& Dixon, R. (2011). Contact force estimation in the railway vehicle wheel-rail interface. IFAC Proceedings Volumes, 44(1), 4398-4403. https://doi. org/10.3182/20110828-6-IT-1002.02904

Welch, G., \& Bishop, G. (2001). An Introduction to the Kalman Filter. University of North Carolina at Chapel Hill Department of Computer Science Chapel Hill, NC 275993175. https://www.cs.unc.edu/ welch/media/pdf/kalman_intro.pdf

Zhao, Y., \& Liang, B. (2013). Re-adhesion control for a railway single wheelset test rig based on the behaviour of the traction motor. International Journal of Vehicle Mechanics and Mobility, 51(8), 1173-1185. https://doi.org/10.1080/00423114.2013.788194

Zhao, Y., Liang, B., \& Iwnicki, S. (2012). Estimation of the friction coefficient between wheel and rail surface using traction motor behaviour. Fournal of Physics: Conference Series, 364(1). https://iopscience.iop.org/article/10.1088/1742-6596/364/1/012004

Zhao, Y., Liang, B., \& Iwnicki, S. (2014). Friction coefficient estimation using an unscented Kalman filter. International Fournal of Vehicle Mechanics and Mobility, 52(suppl. 1), 220-234. https://doi.org/10.1080/00423114.2014.891757 